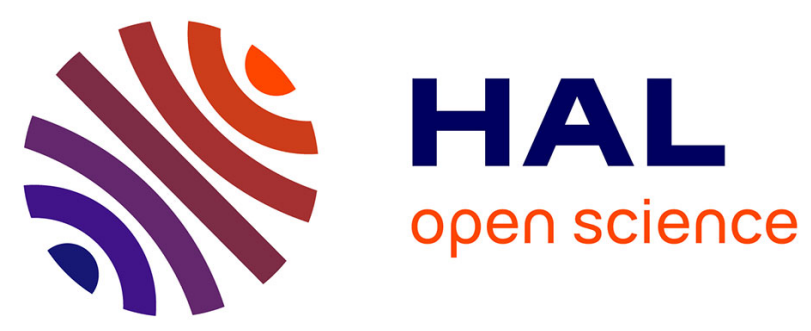

\title{
Defining and implementing a distributed and reconfigurable information system for prognostics.
}

Marie-Danièle Gauvain, Rafael Gouriveau, Noureddine Zerhouni, Christophe Varnier, Nadine Piat, Mike Hessabi

\section{- To cite this version:}

Marie-Danièle Gauvain, Rafael Gouriveau, Noureddine Zerhouni, Christophe Varnier, Nadine Piat, et al.. Defining and implementing a distributed and reconfigurable information system for prognostics.. Prognostic and System Health Management Conference, PHM"11., May 2011, Shenzhen, China. pp.16. hal-00602159

\section{HAL Id: hal-00602159 \\ https://hal.science/hal-00602159}

Submitted on 21 Jun 2011

HAL is a multi-disciplinary open access archive for the deposit and dissemination of scientific research documents, whether they are published or not. The documents may come from teaching and research institutions in France or abroad, or from public or private research centers.
L'archive ouverte pluridisciplinaire HAL, est destinée au dépôt et à la diffusion de documents scientifiques de niveau recherche, publiés ou non, émanant des établissements d'enseignement et de recherche français ou étrangers, des laboratoires publics ou privés. 


\title{
Defining and implementing a distributed and reconfigurable information system for prognostics
}

\author{
A real world integrated predictive maintenance system
}

\author{
Marie-Danièle Gauvain ${ }^{1,2}$, Rafael Gouriveau ${ }^{1}$, Noureddine Zerhouni ${ }^{1,2}$, \\ Christophe Varnier ${ }^{1,2}$, Nadine Piat ${ }^{1}$, and Mike Hessabi ${ }^{2}$ \\ ${ }^{1}$ FEMTO - ST Institute - 24 rue Alain Savary, 25000 Besançon, France \\ Tel : +33 (0)3 814028 01, Fax : +33 (0)3 814028 09, Email : Rafael.Gouriveau@ens2m.fr \\ 2e-m@systec - Temis Innovation, 18 rue Alain Savary, 25000 Besançon, France \\ Tel : +33 (0)8 114655 81, Email : Marie-Daniele.Gauvain@emasystec.com, http://www.emasystec.com
}

\begin{abstract}
According to Condition Based Maintenance practitioners, various activities, ranging from data collection through the recommendation of specific maintenance actions, must be carried out to perform predictive maintenance. Nevertheless, in practice, (and in spite of recommendations like those ones of the OSA-CBM standard), defining and implementing a computer software system for CBM is not a trivial task. That can be mostly explained by the necessity of providing a distributed application that enables to share data and information in an easy but effective manner in-between various actors from various industrial plants. Following that, the aim of the paper is to describe a collaborative software that has been developed in the society e-m@systec. Its simple architecture, as well as its evolving and customizable capabilities make the global information system as useful for distributed applications. The usage of JEE technology improves the portability of the system. This software is well adapted to support predictive maintenance strategies. Thereby and as for an illustration, an example related to a prognostic problem is also described.
\end{abstract}

Predictive maintenance; CBM; e-maintenance platform; modular architecture; prognotic module

\section{INTRODUCTION}

The growth of reliability, availability or safety of a system is a determining factor regarding the effectiveness of industrial maintenance. Thereby, the implementation of provisional strategies is a good way to improve the availability of processes, to ensure the smallest variations of products qualities or the direct costs falling [1]. Furthermore, sustainable development involves the integration of economical strategies beside social and environmental ones for the optimization of processes. This major provocation of triple performance outlined a new and interesting research area: concepts like corrective or preventive maintenance were progressively completed by predictive and proactive maintenance [2]. In these maintenance strategies, "prognostic" takes a growing place and is recognized as a key feature. However, it is obvious that prognostic can not be seen as a single maintenance task as its applicability, cost and effectiveness can vary from an industrial plant to another. Also, the whole aspects of failure analysis and prediction must be viewed as a set of activities that all must be performed. This aspect is highlighted within the Condition-Based Maintenance concept.

According to [3], Condition Based Maintenance "entails the maintenance of equipments based on an assessment of current and projected condition (or health)". The increasing use of CBM strategy (and thereby of CBM systems) is mainly due to the growing needs of reducing maintenance and logistics costs, of improving equipment availability, and of protecting against failure of critical equipments. Also, industrials show a growing interest in this thematic which is becoming a major research framework as mentioned in recent papers [4-6].

Nevertheless, in practice, defining and implementing a computer software system for CBM is not a trivial task. Indeed, beyond the aspects inherent to the usage of "physical" devices like intelligent sensors or table computers, various problems follow from the distributed aspect of the application and the integration effort needed. As for examples, let note the diversity of actors that are involved in a real world application (technicians, managers...), the heterogeneity of useful data (event data, sensor data...), the types of indicators that should be provided, the necessity of exchanging data between the modules and others information systems like SCADA, CMMS and ERP, the goal of operating in a plug-and-play fashion, etc. Following that, the aim of this paper is to discuss some problems that follow from the objective of implementing a distributed CBM information system by describing a real world software suite. The society e-m@systec has developed an emaintenance platform that enables to share data and information in between various actors and applications in order to provide a global distributed maintenance system.

The paper is organized as follows. First CBM concept is briefly described, and the main requirements pointed out in literature to develop a computerized CBM system are given. Then, the software suite from e-m@systec is presented, as well as its components. The whole aims at discussing the distributed and integrative aspects of this platform. Following that, a closer look on the prognostic module definition and implementation is made in order to illustrate the capabilities of such an emaintenance platform. Finally, section V summarizes conclusions of this paper and outlines guidelines for possible futures works.

\section{CBM ARCHITECTURES}

\section{A. CBM systems - an overview}

Many works have been done around the e-maintenance concept like the review on existing platforms provided by [7]. To facilitate the CBM architectures development and to improve the interchangeability of different components, the MIMOSA consortium (Machinery Information Management Open System Alliance) proposed an Open System Architecture for Condition Based Maintenance (OSA-CBM) [3]. As for an application example, let point out the Watchdog 
Agent concept described in [8] that aims at implementing some components of the OSA-CBM in a distributive manner.

OSA-CBM recommends the development of seven types of modules in order to cover the tasks that are useful to perform conditional and predictive maintenances: a sensor module, a signal processing module, a condition monitoring module, a health assessment module, a prognosis module, a decision support module, and a presentation module. These modules are generally represented as communicating thanks to internet or a local network like in Figure 1 [3]. [9] provides an overview of standards that aim at facilitating the development of each one of the modules. Whithin all references, the ISO 13374-2 standard is noticeable in that it has been created to formalize the recommendations of OSA-CBM [10]. This standard can now be seen as a central work, and e-m@systec also wished to base the development of its platform on it.

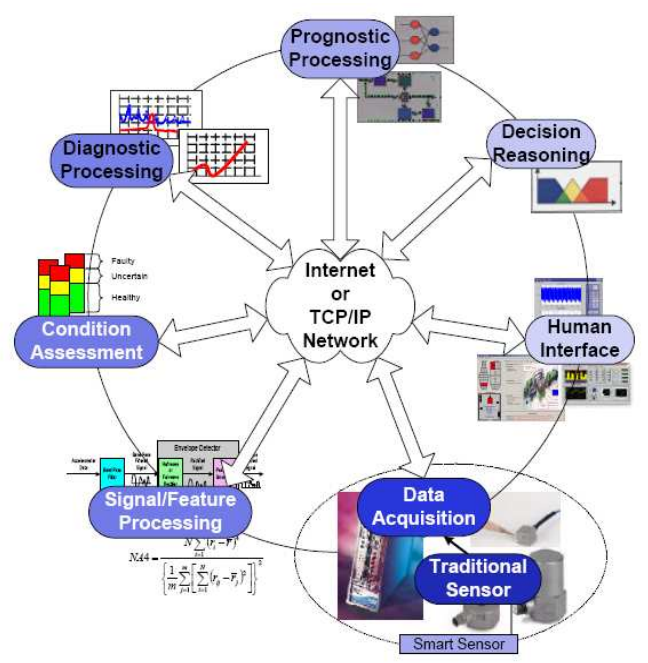

Figure 1. Distributed architecture of Condition Based Maintenance [3]

\section{B. ISO 13374-2 standard}

ISO 13374-2 has been created to facilitate communication between different software for monitoring and diagnosis (CM\&D) [10]. To achieve this goal, the ISO 13374-2 advocates respecting the informational and processing architectures. This processing architecture is composed of 6 blocks (Figure 2).

- The data acquisition (DA) block collects analog, digital and manual data and converts analog data into digital data. The output of the module is digital data with timestamp and data quality indicator.

- The data manipulation (DM) block processes the data in order to extract and select descriptors of interest (features) for the monitoring or diagnosis processes. Inputs from this block are either data from the DA block or from the DM block (cascaded data).

- The state detection (SD) block aims at determining the state of a system or component. It also should generate alerts. SD block may make use of current and historical DA and DM outputs, as well as of SD data if needed (cascade data).

- The health assessment (HA) block determines the current health status of equipment and establishes a diagnosis to determine the cause of the failure. This block uses all data needed from previous blocks. The main outputs are the health grade, the diagnosed faults, the recommendations, the explanation and a level of confidence.

- The block of prognosis (PA) has the primary purpose of determining the future states of an equipment and to estimate its remaining useful life (RUL) for a projected operational context. A level of confidence should also be provided, as well as recommendations and explanations. Any kind of input data shall be used.

- The advisory generation (AG) block aims at integrating information from previous modules and external constraints (availability) in order to recommend optimized actions.

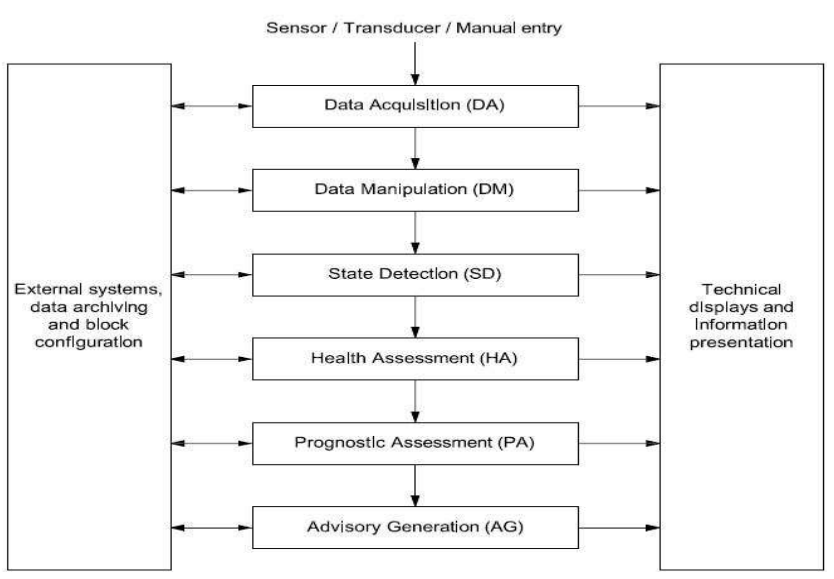

Figure 2. Data processing block diagram - ISO 13374-2 [10]

\section{Implementation requirements}

The processing blocks must be adapted according to real implementation constraints. As for an example, each block needs an important data history whose workflow must be identified. Different algorithms can be used with static or dynamic configurations. The blocks may also have a HumanMachine Interface (HMI). For blocks HA, PA and GA, there are interfaces with external systems to recover past and future actions on equipment and operational data, and to quickly advise when to stop machine for emergency and launch new applications for assistance. The GA module also needs external constraints such as availability, security, cost, etc. The ISO 13374-2 also point out that all modules defined in software may contain the functionality of one or more blocks.

ISO 13374-2 provides the basic requirements for open software architectures information to be processed, communicated, and displayed by various software packages without specific protocols. Beyond the aspects inherent to the usage of "physical" devices like intelligent sensors or table computers, various problems follow from the distributed aspect of the application and the integration effort needed. Notably, which is the good way to implement a CBM architecture considering the data heterogeneity, the need of exchanging data between the modules and other information systems? Indeed, this aspect is unavoidable for real industrial applications: all maintenance actors do not require the same information. Also, they must be provided with contextual information. The purpose of next section is to present an architecture that enables to face with those problems. This architecture has been developed at e-m@systec in the framework of SMAC project (Semantic-maintenance and life cycle) (see Acknowledgment section). 


\section{E-M@SYSTEC SOFTWARE SUITE : A DISTRIBUTED AND RECONFIGURABLE INFORMATION SYSTEM}

A. e-m@systec software suite overview

e-m@systec global solution aims at providing advanced functionalities to simplify maintenance tasks in practice, from management to implementation. To perform the various maintenance activities (planning of interventions, inventory management, diagnostics, monitoring, maintenance strategies selection, etc.), the required information must be easily accessible and exchanged. That can be obtained thanks to the main core "e-m@web" of the software suite that allows the data centralization and redistribution (Figure 3). Let have a look on the 4 main major features that follow from it.

1) Access to data from the control/command at the operational level: the connection to SCADA (Supervisory Control And Data Acquisition) systems enables e-m@web to gather the data provided by sensors.

2) Access to available information in dedicated software tools: e-m@web interfaces the information coming from the maintenance-oriented systems tools such as DMS (Document management system), CMMS (Computerized Maintenance Management System) and ERP (Entreprise Resource Planning).

3) Provide specific applications for the implementation of an intelligent maintenance: e-m@web also offers specific modules dedicated to the anticipation (e-m@pron), the failure diagnostics (e-m@diag), the optimization of spare parts and interventions (e-m@log).

4) Facilitate representation with a HMI (Human-Machine Interface) offering contextualized access: the em@real module provides support for the maintenance interventions.

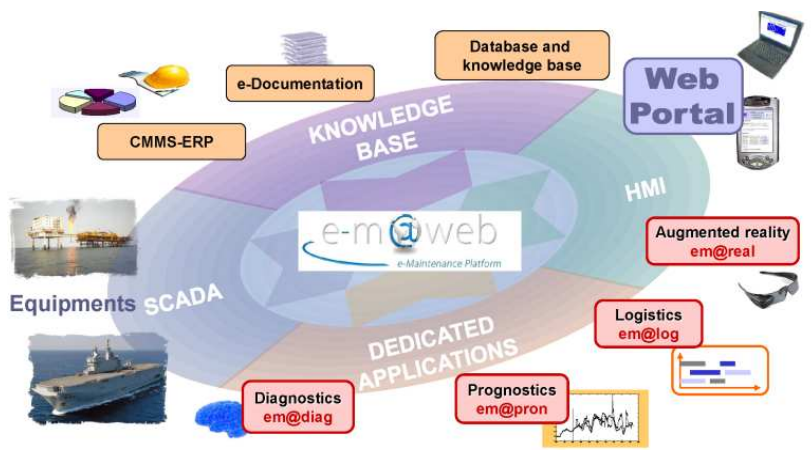

Figure 3. e-m@systec software suite architecture

The software suite of e-m@systec is notably composed of e-m@web, e-m@diag and e-m@pron, whose main functionalities are the following. Event and sensor data are centralized by e-m@web, which can connect to different CMMS, ERP and SCADA systems to retrieve relevant data for the various maintenance processes. The module e-m@diag is a diagnosis module that is based on knowledge capitalization techniques like case-based reasoning. Prognostics of progressive failure are performed thanks to the e-m@pron module.

These three main modules are obviously not sufficient to perform support to a global maintenance. The e-m@sytec software suite integrates thereby the remaining functionalities defined in ISO 13374-2. An illustration is given in Figure 4 and can be briefly described as follows.
- The DA module is found in the CMMS data for event data such as work requests, the stock of spare parts and ERP data for event data such as the cost of spare parts and in the SCADA for sensor data;

- The DM module is a part in the SCADA and one other in e-m@web;

- The SD module is also located either in the SCADA or in e-m@web;

- The HA module is in e-m@diag module;

- The PA module is in e-m@pron module;

- The AG module is the element the most important of e-m@web that use all data of the other tools.

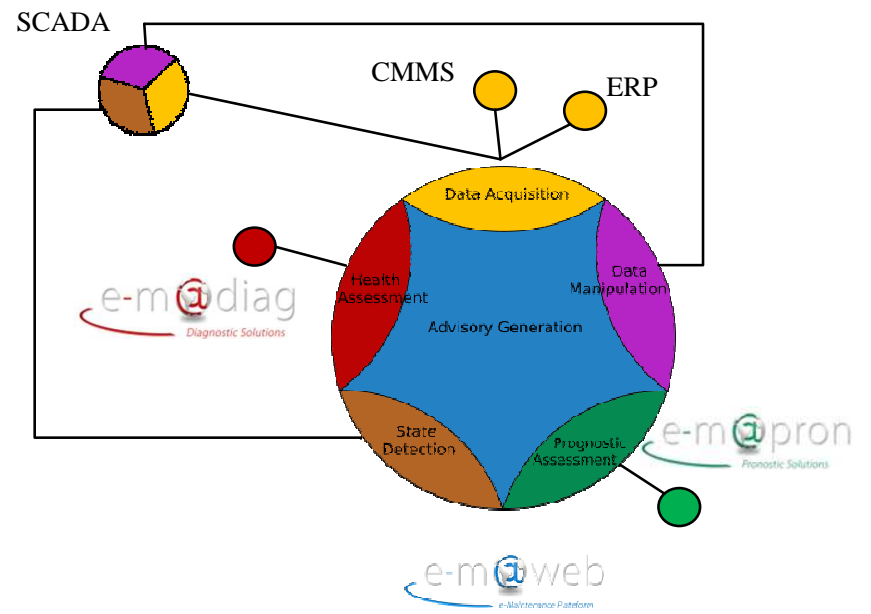

Figure 4. Blocks of ISO 13374-2 in the software suite of e-m@systec

\section{B. The e-m@systec software suite as an integrating system}

The e-m@systec software suite is a distributed, modular, portable and reconfigurable platform. Main advantages of these characteristics are the followings.

- The interest of a distributed platform is to perform the computations on different machines in order to reduce the global complexity of implementation. Another advantage is the exchange of experiences from various maintenance sites that enriches the knowledge base.

- The modular platform enables to use only the necessary functionality. For example, if only conditional and corrective maintenances are required, there is no need to install the e-m@pron module.

- Work environment constraints as operating systems, Windows or Linux, are no longer a problem thanks to the portability of the software suite.

- Reconfigurability allows the adaptation of the platform to any maintenance system according to specific needs.

Three aspects are at least relevant to discuss the main characteristics of the software suite.

\section{1) Several actors}

Different actors can access the e-m@systec software suite. Depending on the connected role, contextual information varies. There are 5 different roles (administration roles are not considered here): the production operator, the maintenance worker, the manager, the expert and the top manager, as can be seen in Figure 5. 




Figure 5. Actors diagram of the software suite

The production operator is the user of maintained equipments. This role creates a work request for corrective maintenance when an equipment failure occurs. The maintenance worker is responsible of the maintenance task of equipments. The manager oversees the maintenance and human resources, and can access to all information related to his team. The top manager checks if the objectives are met and therefore has access to available indicators. The expert provides his knowledge and feedback on the equipments, for example, the configuration of e-m@diag and e-m@pron must be performed by an expert. These different roles are the default roles to facilitate the implementation of the platform. According to specific requirements and thanks to the reconfigurability characteristic of the platform, appropriate roles can however be created as needed.

\section{2) Technology}

In order to implement a distributed system, the various elements developed within the e-m@systec software suite are in the portable language JEE (Java Entreprise Edition), which facilitates the creation of distributed applications. More precisely, implementation is performed thanks to the Jboss free application server, which is the most commonly used. It uses the Seam framework that eases the development of Web applications, and the integration of JSF (JavaServer Faces), EJB 3 (Enterprise Java Bean) and JPA (Java Persistence API). JSF is a user interface framework. EJB is a reusable component designed to be deployed on application servers. JPA is an interface defining the mapping of objects within the database. The used database is PostgreSQL. A thin client is used, which has the advantage to require only a web browser to be installed. Figure 6 shows the various elements described above.

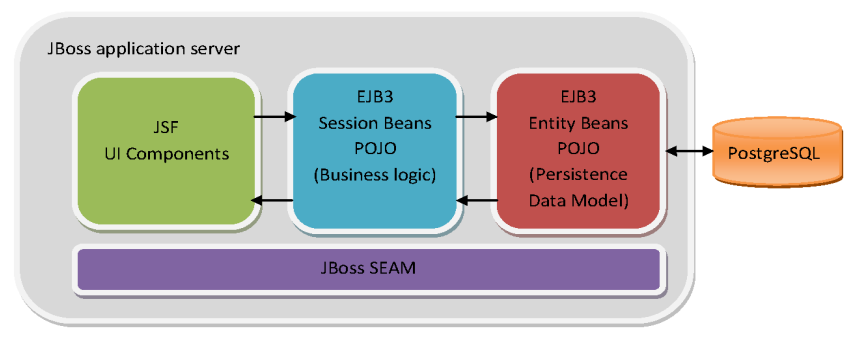

Figure 6. Technology representation

\section{3) Communication between the differents modules}

The e-m@web module has many ways to communicate with different tools depending on their technology. Between 2 e-m@systec tools, communication is done using EJB Session, which provides a service to customers via the RMI (Remote
Method Invocation) protocol. Various web services are provided by PcVue, which is a SCADA. For example em@web can ask PcVue to return the last value of a sensor. There is also a connection with socket that is a lower levels' protocol. For example, the communication between a sensor of Senseor [11] (one of e-m@systec parterns) and e-m@web is made by socket. The different types of communication are shown in Figure 7.

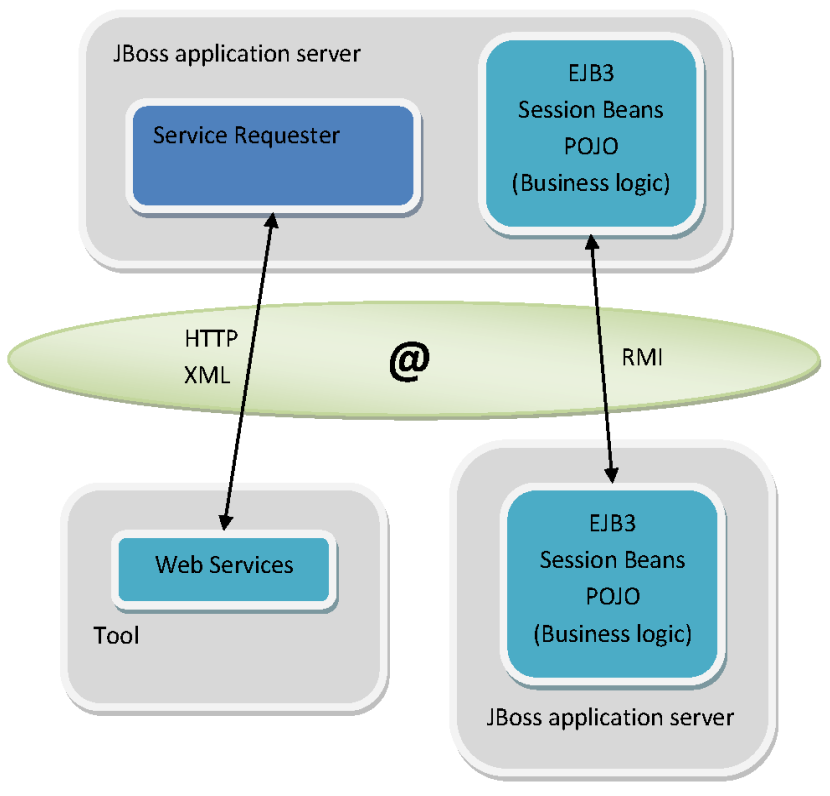

Figure 7. Communications representation

\section{EXEAMPLE OF IMPLEMENTATION : THE PROGNOSTICS MODULE}

\section{A. Scenario and informational flow}

The aim of the prognostic process is to determine when a machine will be considered as in a failure mode, and to give this information at the right time and at the right person, in order to open a work request if necessary. Let's take a simple scenario to illustrate these needs.

In a few words, there is an informational flow from the sensor to the practitioner in charge of managing the maintenance task. This flow can be schematized as depicted in Figure 8. (For clarity reasons and in order to illustrate the complementarities of e-m@systec modules, same colors than those of Figure 4 have been used). The first step is performed by the e-m@pron module that aims at saving the relevant data on the behavior of the equipment under study (thanks to monitoring devices), at estimating future values of these descriptors, and at performing a classification step in order to provide the health state of the equipment at any time. According to this last information, an alert or alarm can be raised (or not) which can finally lead to generate a work request and send emails to the maintenance manager.

Figure 9 depicts the information flow by taking into account the architecture of the e-m@systec software suite. (Here again, colors from Figure 4 are maintained). Two sites are represented: the first one is the manufactory in which the maintained equipment is located, and the other one states for a remote building in which can be located the manager. The manufactory has a SCADA and a server that houses the SCADA connector and the e-m@pron module. An other server is situated in the building and houses the remote e-m@web. 


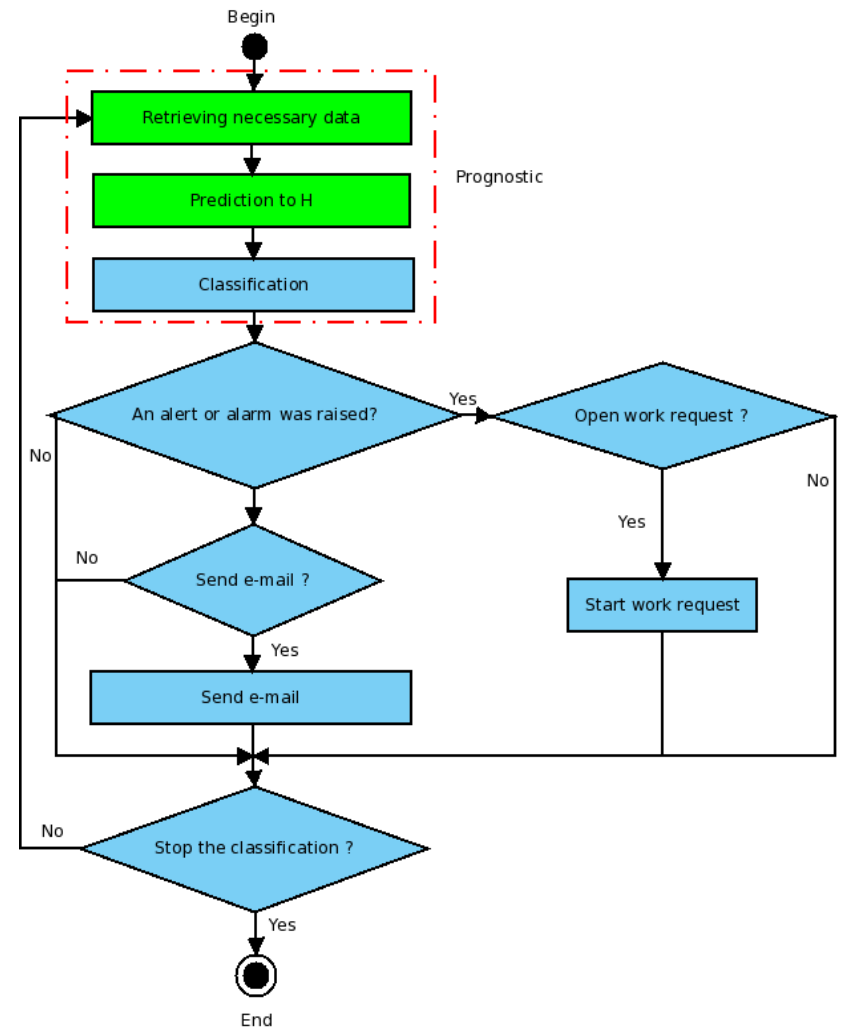

Figure 8. Prognostics scenario - informational flow

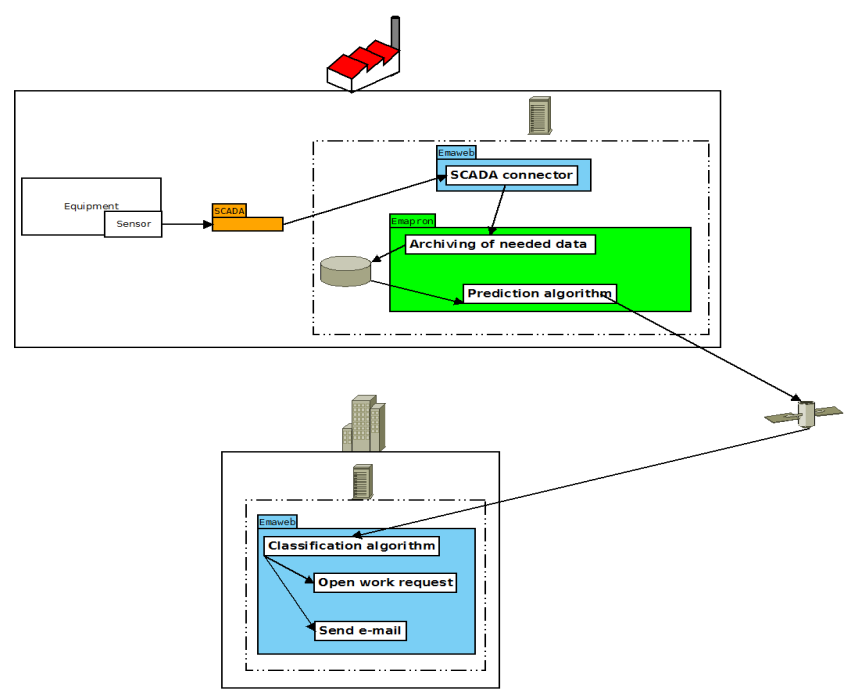

Figure 9. Prognostics scenario - architecture

\section{B. Performing prognostics}

As briefly explained before, 3 steps are needed to perform prognostic: data archiving, prediction and classification.

\section{1) Data archiving}

To forecast, the e-m@pron module needs to make an interesting data archiving. This can be made thanks to a functionality of e-m@web: the historization of data (named the SCADA connector) that aims at labeling all data with an index of time, and at transmitting them to e-m@pron module. This last one is able to archive those data.

\section{2) Prediction}

Prediction aims at estimating the future values of data until a forecasting horizon set by the user. For that purpose, the e- m@pron module is based on the uses of a neuro-fuzzy system as a prediction tool. The underlying algorithm is presented in [12] and is based on an exTS (evolving extended TakagiSugeno system).

\section{3) Classification}

The remote e-m@web module houses a classification functionality which calculates a set period. The classification aims at transforming the predicted values at any time " $t+h$ " into most probable classes describing the health state of the equipment (normal, degraded, critical behavior). Eeach classification requires thereby results from the prediction algorithm of e-m@pron module. When classification is performed, whether a warning or an alarm is raised and em@web can create new work request and / or send an email to the person concerned by the information.

\section{Degradation data simulation}

The aim of this part is to illustrate the scenario with a simulation. The simulated degradation is a first-order chemical reaction introduced by [13]. It describes the growth of failurecausing conducting filaments of chlorine-copper compounds in printed-circuit boards. Let note $\mathrm{CH}_{1}$ the amount of chlorine available for reaction and $\mathrm{CH}_{2}$ a proportion of the amount of failure-causing chlorine-copper compounds at time " $t$ ". Under appropriate conditions of temperature, humidity, and electrical charge, there is a chemical reaction in which copper combines with chlorine $\left(\mathrm{CH}_{l}\right)$ to produce $\left(\mathrm{CH}_{2}\right)$ with a constant degradation rate $\left(r_{l}\right)$ :

$$
\mathrm{CH}_{2}(t)=\mathrm{CH}_{1}(0) \cdot\left[1-\exp \left(-r_{1} \cdot t\right)\right]
$$

where $\mathrm{CH}_{l}(\mathrm{O})$ is the initial amounts of chlorine available for reaction.

In this paper, the proposed approach to perform prognostic assumes that no understanding of the degradation phenomena is necessary as the exTS predictor would track it. Thus, the mathematical expression in (1) was not used as a model but to generate realistic simulation data: this was done by simulating degradation rates $\left(r_{l}\right)$ and by adding a random value (uniform distribution) as a noise to the calculated value of $\mathrm{CH} 2(t)$.

An amount of 150 degradation data samples were generated and entered into the SCADA as if it would have been provided by a real plant (Figure 10). Following that, data where stored thanks to the data archiving functionality of e-m@pron, and were used to train the predictive model.

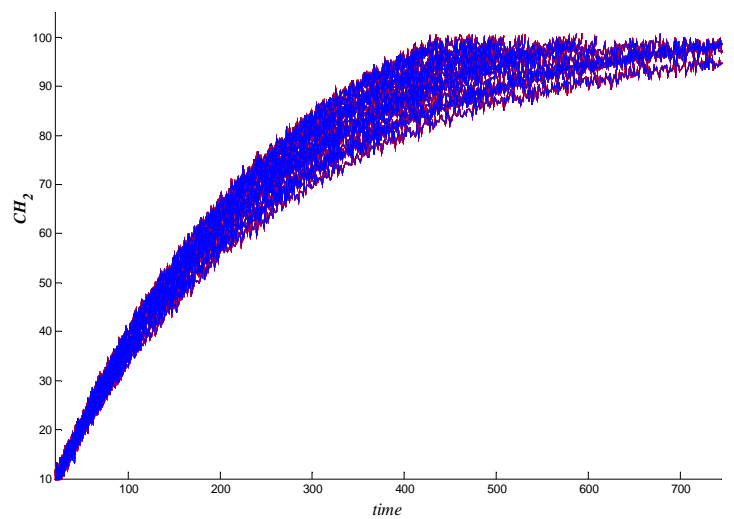

Figure 10. Degradations dataset

Another degradation data sample has been generated to be used as a data simulation. When applying, e-m@pron module provides future values. For that purpose, at any time " $t$ ", 4 
regressors (the 4 last data) were used as inputs from the prediction system (the exTs system) in order to perform predictions at " $t+1$ ". Multi-step ahead predictions (at any $" t+h ")$ were performed by applying the cascade techniques that aims at using results from prediction at " $t+i$ " as inputs for prediction at " $t+i+1$ ". This configuration is realized by an expert and other type of long term approaches can be considered. In experiments, predictions were provided from time "50". Figure 11 depicts the results as presented by em@pron module.

The classification step is configured by an expert role. In this example a threshold of $85 \%$ of chlorine-copper compounds was set as critical with respect to the application (i.e. limit for the failure mode). When this limit is exceeded, an alert is triggered and an email is send to the manager. At any time, an email can also be sent to inform from the remaining useful life (RUL) of the equipment (in this example, failure will probably occurs on November the $28^{\text {th }}$ between $5 \mathrm{~h}$ and $6 \mathrm{~h}$. A work request can thereby be performed in order to start with the scheduling of the maintenance task.

\section{e-m@pron home em@web em@pronsettings}

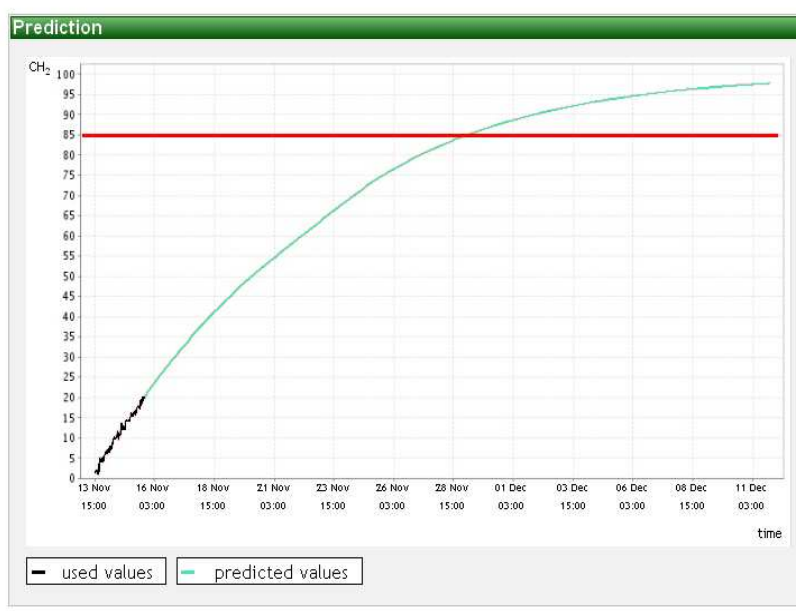

Figure 11. Simulation result

\section{CONCLUSIONS}

Conditional Based Maintenance (CBM) and predictive maintenance are now considered as key feature since the uses of provisional strategies is a good way to improve the availability of processes, to ensure the smallest variations of products qualities or the direct costs falling. Nevertheless, in practice (and in spite of recommendations like those ones of the OSA-CBM standard), defining and implementing a computer software system for CBM is not a trivial task. That can be mostly explained by the necessity of providing a distributed application that enables to share data and information in an easy but effective manner in-between various actors from various industrial plants. Following that, the aim of the paper was to describe a collaborative software that has been developed in the society e-m@systec. The global software suite and some of its functionalities and modules have been described. Its simple architecture, as well as its evolving and customizable capabilities make the global information system as useful for distributed applications. The usage of JEE technology improves the portability of the system. This software is well adapted to support predictive maintenance strategies. Thereby and as for an illustration, an example related to a prognostic problem has also been described. For that purpose, a scenario of a prognostic application has been presented in order first, to illustrate the informational flow that is required, and secondly to show what characteristics of the software suite are powerful to perform this type of maintenance activity.

\section{AKNOWLEDGMENT}

This work has been carried out and partially fund in the framework of SMAC project (Semantic-maintenance and life cycle), supported by European program Interreg IV between France and Switzerland.

\section{REFERENCES}

[1] J-B. Leger and G. Morel, "Integration of maintenance in the enterprise: towards an enterprise modelling based framework compliant with proactive maintenance strategy", Production Planning and Control, vol. 12:2, pp. 176-187, 2001.

[2] A. Muller, M. Suhner and B. Iung, "Formalisation of a new prognosis model for supporting proactive maintenance implementation on industrial sytem", Reliability Engineering and System Safety, vol. 93, pp. 234-253, 2008.

[3] M. Lebold and M. Thurston, "Open standards for condition-based maintenance and prognostic systems", in: Proc. 5th Annual Maintenance and Reliability Conference, Gatlinburg, USA, 2001.

[4] F-E. Ciarapica and G Giacchetta, "Managing the condition-based maintenance of a combined-cycle power plant: an approach using soft computing techniques", Journal of Loss Prevention in the Process Industries, vol. 19, pp. 316-325, 2006.

[5] A. Heng A, S. Zhang, A. Tan and J. Matwew, "Rotating machinery prognostic: State of the art, challenges and opportunities", Mechanical Systems \& Signal Processing, vol. 23, pp. 724-739, 2009.

[6] A-K-S. Jardine, D. Lin and D Banjevic, "A review on machinery diagnostics and prognostic implementing condition-based maintenance", Mechanical Systems \& Signal Processing, vol. 20, pp. 1483-1510, 2006.

[7] A. Muller, A. Crespo Marquez, et B. Iung, "On the concept of emaintenance: Review and current research," Reliability Engineering \& System Safety, vol. 93, Aoû. 2008, p. 1165-1187.

[8] D. Djurdjanovica, J. Lee and J. Ni, "Watchdog Agent - an infotronicsbased prognostics approach for product performance degradation assessment and prediction", Advanced Engineering Informatics, vol. 17, pp. 109-125, 2003.

[9] M. Bengtsson, "Condition based maintenance system technologywhere is development heading?", in: Proc. 17th European Maintenance Congress Euromaintenance, Barcelona, Spain, 2004.

[10] ISO 13374-2, "Condition monitoring and diagnostics of machines Data processing, communication and presentation - Part 2: Data processing", International Standard, ISO, 2007.

[11] Senseor. http://www.senseor.com/

[12] M. El-Koujok, R. Gouriveau, et N. Zerhouni, "Error estimation of a neuro-fuzzy predictor for prognostic purpose", in: Proc: 7th IFAC Int. Symp. SAFEPROCESS 2009.

[13] W.Q. Meeker et M.J. LuValle, “An Accelerated Life Test Model Based on Reliability Kinetics," Technometrics, vol. 37, Mai. 1995, p. 133146. 